\title{
Can patients apply the Ottawa ankle rules to themselves?
}

\author{
J E J Blackham, T Claridge, J R Benger
}

\begin{abstract}
- Figures 1 and 2 and the information sheet and pictorial questionnaire describing the Ottawa ankle rules is shown in Appendix 1 published online only at http://emj.bmj.com/content/ vol25/issue11

Academic Department of Emergency Care, Emergency Department, United Bristol Healthcare Trust, Bristol, UK

Correspondence to:

Dr J R Benger, Academic Department of Emergency Care, Emergency Department, United Bristol Healthcare Trust, Bristol BS2 8HW, UK; jonathan. benger@ubht.nhs.uk
\end{abstract}

Accepted 17 April 2008

\begin{abstract}
Objective: To determine whether patients with an ankle injury obtained the same results as clinicians when applying the Ottawa ankle rules (a validated clinical decision rule) to themselves.
\end{abstract}

Methods: Patients aged $>15$ years presenting to an inner city emergency department within $48 \mathrm{~h}$ of an ankle injury were asked to assess their own injury using the Ottawa ankle rules. The results of their self-assessment were compared with those of a treating clinician.

Results: Poor interobserver agreement was found between patients and clinicians.

Conclusions: Making the Ottawa ankle rule more widely available to the general public is unlikely to reduce healthcare demand. Indeed, given the apparently low specificity of the rule, demand could actually increase as a result.

The Ottawa ankle rules have been extensively validated as a clinical decision rule for use by healthcare professionals in detecting possible bony injury - and therefore the need for radiography - in patients with a recent ankle injury. ${ }^{1}$ The sensitivity of these rules closely approaches $100 \%$, and they have been widely adopted. ${ }^{2}$ The Ottawa ankle rules can be reliably applied by a range of healthcare professionals, including emergency nurse practitioners. ${ }^{3}$ If they could also be reliably applied by patients to their own ankle injuries, there is the potential to reduce healthcare consultations following ankle sprain with consequent resource savings, particularly if the rules were widely publicised.

The aim of this pilot study was to determine the agreement between patients and clinicians when applying the Ottawa ankle rules, and therefore whether adult patients with a recent ankle injury are potentially able to accurately apply the Ottawa ankle rules to themselves.

\section{METHODS}

A convenience sample of 50 patients attending a single inner city emergency department with a recent (within $48 \mathrm{~h}$ ) ankle injury were asked if they wished to participate in the study by a researcher triaging the patient. All patients were offered analgesia. Patients who elected not to enter the study were examined by a researcher and treated according to usual practice. If the patient entered the study, informed written consent was obtained and they were then given an information sheet and pictorial questionnaire describing the Ottawa ankle rules (see online Appendix 1). Participants were asked to examine their own ankle and to enter the results on the questionnaire before formal clinical assessment.
The patient was then seen by an emergency department clinician (doctor, emergency nurse practitioner or extended scope physiotherapist) who was blind to the patient's assessment of his or her own injury. The clinician made an independent assessment of the injury and arranged radiographs as appropriate. The clinician then completed a study questionnaire giving details of his/her assessment and an interpretation of any radiographs. The formal radiology report was also reviewed and, where any disagreement occurred, the radiology report was taken as the reference standard. If radiography was not performed, the emergency and radiology department records were checked to see if the patient presented in the following month with a lower limb injury.

The kappa statistic was used to determine the level of agreement between the patient and clinician, with $\chi^{2}$ testing to compare their overall opinion.

\section{RESULTS}

Fifty patients (25 men, 25 women) of mean age 32 years (range 16-63) were recruited to the study. The mean duration from injury to presentation was $17 \mathrm{~h}$.

All 50 patients rated themselves as positive on at least one of the five Ottawa criteria, and therefore all patients concluded that they required a radiograph. On examination by the clinician, 45 of the 50 patients were positive on at least one of the Ottawa criteria and therefore required a radiograph. Of the remaining five patients, one had a ruptured Achilles tendon and one underwent radiography for other reasons. None of the other three patients who did not undergo radiography returned to the emergency department or had lower limb radiographs at the same hospital during the following month.

Of the patients who underwent radiography, seven (14\%) had fractures identified by both the clinician and the reporting radiologist. Three (6\%) had fractures suspected by the clinician but not confirmed by the radiologist. The remaining 36 patients (72\%) who had radiographs did not have a fracture. No fractures were missed by an ED clinician.

Agreement between the patient and clinician in relation to each of the five Ottawa criteria is shown in tables 1 and 2. There was very little agreement between patients and clinicians on whether they could walk initially or in the emergency department, but greater agreement regarding local tenderness. Overall, $90 \%$ of clinicians and $100 \%$ of patients rated the rule as positive, demonstrating a statistically significant difference between the final opinions of the two groups ( $p=0.02, \chi^{2}$ test). The kappa values shown 
Table 1 Results of patient and clinician examinations

\begin{tabular}{lcc}
\hline & \multicolumn{2}{c}{ Patient } \\
\cline { 2 - 3 } Clinician & Yes & No \\
\hline Walk immediately/in ED & & \\
$\quad$ Yes & 6 & 15 \\
$\quad$ No & 18 & 11 \\
Lateral malleolus tenderness & & \\
$\quad$ Yes & 21 & 7 \\
$\quad$ No & 4 & 18 \\
Medial malleolus tenderness & & \\
$\quad$ Yes & 11 & 2 \\
$\quad$ No & 11 & 26 \\
Navicular tenderness & & \\
$\quad$ Yes & 12 & 4 \\
$\quad$ No & 2 & 32 \\
Base of fifth metatarsal tenderness & & \\
$\quad$ Yes & 6 & 6 \\
No & 9 & 29 \\
$\quad$
\end{tabular}

Table 2 Agreement between patients and clinicians

\begin{tabular}{llll}
\hline & $\begin{array}{l}\text { Patients and } \\
\text { clinicians } \\
\text { agree }\end{array}$ & $\begin{array}{l}\text { Patients and } \\
\text { clinicians } \\
\text { disagree }\end{array}$ & Kappa value (95\% Cl) \\
\hline Walk immediately/in ED? & 17 & 33 & $-0.32(-0.06$ to -0.59$)$ \\
Lateral malleolus tenderness & 39 & 11 & $0.56(0.33$ to 0.79$)$ \\
Medial malleolus tenderness & 37 & 13 & $0.45(0.18$ to 0.71$)$ \\
Navicular tenderness & 44 & 6 & $0.71(0.50$ to 0.93$)$ \\
Base of fifth metatarsal & 35 & 15 & $0.24(0.00$ to 0.54$)$ \\
tenderness & & & \\
Ottawa ankle rules & 45 & 5 & \\
\hline
\end{tabular}

in table 2 also indicate generally poor agreement between the patients and clinicians.

\section{DISCUSSION}

This study found very little agreement between patients and healthcare professionals when applying the Ottawa ankle rules. All patients found that their injury was positive on at least one criterion and therefore required a radiograph, and this may have influenced their assessment. ${ }^{4}$ However, $90 \%$ of patients had at least one positive criterion on clinician assessment, and all but $8 \%$ of patients underwent radiography.

The fact that patients and clinicians agreed on the overall result in $90 \%$ of cases is attributable to the fact that the rule was judged positive in $100 \%$ of patients and $90 \%$ of clinicians. On closer examination of the data it is clear that the reasons for a positive overall result differed greatly. In general there was poor agreement in each section of the decision rule, particularly the ability to weight-bear both immediately after the injury and in the ED, where there is less agreement than would be expected by chance alone and therefore a negative kappa value. This suggests that weight-bearing may be harder to interpret than local tenderness.

A weakness of the study is that five patients who did not have radiographs were not directly followed up. These patients could have attended another hospital for further investigation. However, the primary aim of the study was not to assess the diagnostic accuracy of the rule (which is already well demonstrated), ${ }^{2}$ but rather to examine the interobserver agreement at the time of presentation. Other weaknesses include the use of a small convenience sample and the fact that patients were made aware that the Ottawa rules are used by clinicians to decide
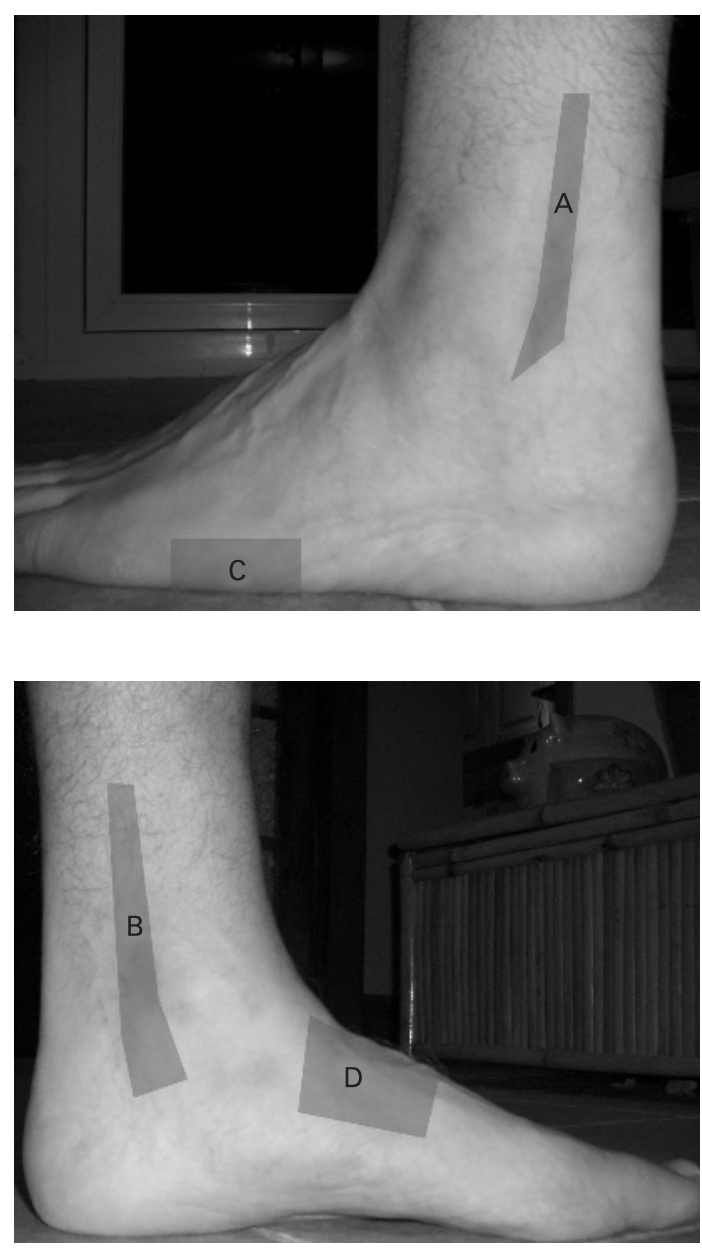

whether a radiograph is required, potentially biasing their selfassessment. However, it is clear that agreement between clinicians and patients is poor and, in the light of these results, there may be little opportunity to reduce healthcare demand by making this clinical decision rule more widely available to the general public. Indeed, given the apparently low specificity of the rule, demand could actually increase as a result.

\section{CONCLUSION}

This study showed poor interobserver agreement between clinicians and patients in the assessment of ankle injuries using the Ottawa ankle rules. All patients felt they needed a radiograph compared with $90 \%$ of clinicians.

Acknowledgements: The authors thank Dr Adam Brown for his assistance with patient recruitment.

Funding: None.

Competing interests: None.

Ethics approval: The study was approved by the North Bristol research ethics committee and written informed consent was obtained from trial participants.

\section{REFERENCES}

1. Stiell IG, Bennett C. Implementation of clinical decision rules in the emergency department. Acad Emerg Med 2007;14:955-9.

2. Bachmann LM, Kolb E, Koller MT, et al. Accuracy of Ottawa ankle rules to exclude fractures of the ankle and mid-foot: systematic review. BMJ 2003;326:417-9.

3. Mann CJ, Grant I, Guly H, et al. Use of the Ottawa ankle rules by nurse practitioners Emerg Med J 1998;15:315-6.

4. Wilson DE, Noseworthy TW, Rowe BH, et al. Evaluation of patient satisfaction and outcomes after assessment for acute ankle injuries. Am J Emerg Med 2002;20:18-22. 